\section{Habitat fragmentation}

The body of evidence on the threats to biodiversity caused by habitat fragmentation is constantly growing and this is particularly true in areas where the problem is most critical, as illustrated by three recent studies from central Amazonia.

An 18-year experimental study assessing the effects of rain-forest fragmentation on tree community dynamics, found that mean tree mortality, damage and turnover rates were much higher close to fragment edges than in continuous forest and the effects were still noticeably different up to $300 \mathrm{~m}$ from forest edges (Laurance et al., 1998). A model incorporating the data suggested that edge effects, apparently the result of increased windthrow and microclimatic changes, were greatest in small fragments (100-400 ha) and that forest structure, floristic composition, biomass, microclimate and, ultimately, disturbance-sensitive species will all be affected by fragmentation.

Leaf-litter beetles in a fragmented tropical landscape, showed significant responses to edge effects and fragment area. Of 32 species found in contiguous forest, 48.9 per cent had disappeared from 1 ha, 29.8 per cent from $10 \mathrm{ha}$, and 13.8 per cent from 100-ha forest fragments. Declining density was a significant precursor to species loss from fragments and, interestingly, common rather than rare species were more likely to become locally extinct in small fragments (Didham et al., 1998). A further experimental study investigating the rates of leaf-litter decomposition in fragmented and continuous forest found that fragmentation increased the variability and unpredictability of litter decomposition (Didham, 1998). Measurements taken along forest-edgeto-interior transects and at the centres of different-sized fragments, showed that litter decomposition rates were faster at the edges than in the interiors of large forest fragments, but no difference was found from interior to edge of continuous forest. Decomposition rates were also strongly affected by decreasing fragment area with lower rates at the centre of small fragments. As decomposers of dead organic matter are performing one of the key functions of maintaining healthy ecosystems, the importance of the effects of fragmentation on this group cannot be underestimated.

Investigation of the tolerance to, and use of, the edge and surrounding matrix of agricultural land by nine species of small mammals in fragmented Atlantic forest in Sergipe, Brazil, found that small mammal diversity increased with distance from fragment edges. No small mammals were captured in the surrounding farmland and a very small number of only three of the nine study species were captured along the edge of fragments (Stevens \& Husband, 1998). The type of landscape surrounding fragmented habitats may have an effect on the abundance of some species in the remaining fragments. Small mammals in a southern boreal mixed-wood in Saskatchewan, which had been subject to fragmentation as a result of both logging and agricultural activity, were less abundant in patches surrounded by logging clearcuts than in either contiguous forest or forest fragments surrounded by agricultural land. Indeed the type of surrounding habitat appeared to be more important than fragment size or area of edge when determining species abundance. The reasons for this were not clear but could have been the result of some species using the clearcut areas as an alternative habitat (Byrne \& Hobson, 1998).

Fragment size and degree of isolation can have a synergistic effect, particularly for some plant species. Experimental work on an annual herb, Clarkia concinnia, has shown that pollinators were not as effective at finding small isolated patches as they were at finding large ones, and small isolated patches suffered greater reproductive failure and extinction rates as a result (Groom, 1998). Increasing fragmentation and decreasing fragment size have also been shown to increase predation risk from large predators on Neotropical ground nesting passerine birds in northeastern Alabama, a factor which could be partially responsible for recent population declines (Keyser et al., 1998).

The fragmentation of habitats can help to increasing the survival rate of insect pests and assist in the establishment of invading exotic species. In a study in Ontario, Canada, the forest tent caterpillar Malocosoma disstria, the most destructive pest of trembling aspen, Populus tremuloides, survived better in edge areas with - less forest cover than in the forest interior (Rothman \& Roland, 1998). Increased mortality of the caterpillar in greater forest cover was due to a virus and presence of parasitoids. In fragments of scrub habitat in coastal southern California, an exotic species, the Argentine ant Linepithema humile, was found to thrive near developed edges and in areas dominated by exotic vegetation, to the detriment of native ant species, particularly army ants Neivamyrmex spp. and harvester ants, genera Messor and Pogonomyrmex, both of which are important to ecosystem-level processes. The abundance of Argentine ants, fragment size and time since isolation were the best predictors of the number of remaining ant species, which declined from an average of more than seven species to less than two when Argentine ants were present (Suarez et al., 1998). 
However, all is not doom and gloom. Research investigating the structure of natural fragments of forest that were part of once-continuous forest which fragmented and retreated over time during drought conditions in the Pleistocene, may give clues to the best way to protect habitats from the worst effects of fragmentation. Based on their findings, Kellman et al. (1998) have suggested that creating stable protective edge communities containing fire insensitive trees around new fragments, and providing connections between fragments for bird dispersers may help to preserve fragmented habitats and protect the species living within them.

\section{Jessamy Battersby}

\section{References}

Bayne, E.M. \& Hobson, K.A. (1998) The effects of habitat fragmentation by forestry and agriculture on the abundance of small mammals in the southern boreal mixedwood forest. Canadian Journal of Zoology, 76, 62-69.

Didham, R.K. (1998) Altered leaf-litter decomposition rates in tropical forest fragments. Oecologia, 116, 397-406.

Didham, R.K., Hammond, P.M., Lawton, J.H., Eggleton, P. \& Stork, N.E. (1998) Beetle species responses to tropical forest fragmentation. Ecological Monographs, 68(3), 295-323.

Groom, M.J. (1998) Allee effects limit population viability of an annual plant. The American Naturalist, 151 (6), 487-496.

Kellman, M., Tackaberry, R. \& Rigg, L. (1998) Structure and function in two tropical gallery forest communities: implications for forest conservation in fragmented systems. Journal of Applied Ecology, 35, 195-206.

Keyser, A.J., Hill, G.E. \& Soehren, E.C. (1998) Effects of forest fragment size, nest density, and proximity to edge on the risk of predation to ground-nesting passerine birds. Conservation Biology, 12(5), 986-994.

Laurance, W.F., Ferreira, L.V., Rankin-de Merona, J.M. \& Laurance, S.G. (1998) Rain forest fragmentation and the dynamics of Amazonian tree communities. Ecology, 79(6), 2032-2040.

Rothman, L.D. \& Roland, J. (1998) forest fragmentation and colony performance of forest tent caterpillar. Ecography, 21, 383-391.

Stevens, S.M. \& Husband, T.P. (1998) The influence of edge on small mammals: evidence from Brazilian Atlantic forest fragments. Biological Conservation, 85, 1-8.

Suarez, A.V., Bolger, D.T. \& Case, T.J. (1998) Effects of fragmentation and invasion on native ant communities in coastal southern California. Ecology, 79(6), 2041-2056.

\section{Protected areas}

The loss of natural habitats has put pressure on conservationists to protect and manage as much as possible of what is remaining. To this end recent research has concentrated on finding the best method for selecting sites for protection, which will maximize the number of species protected while minimizing the time and money spent. Traditional methods using surrogate information to gauge biodiversity of an area, such as the species richness of certain indicator species, overall endemism, or genus or family richness, appear to be limited in application as richness hotspots for different taxa, and hotspots and rare taxa seldom coincide (Van Jaarsveld et al., 1998; Reid, 1998). Another method, complementarity, where an area is divided into grids and sets of grids that contain all species in a taxon at least once are included for protected status, was recently assessed and also showed little overlap between sets of species (Van Jaarsveld et al., 1998).

However, complementarity as a method for protected-area selection can be useful under certain circumstances. In Uganda, a major study looking at 2452 species across 50 forest areas found little spatial congruence in species richness between different groups of animals and plants (Howard et al., 1998), but when priority forest sites were selected using a single group of species, often species richness of other groups was captured with the same efficiency as when using data on all groups at once. Data on birds and butterflies were as good as or better than data on all groups for picking forest areas with generally high species richness, but data on plants were not.

Complementarity appears to be a useful method when looking at single-taxon conservation. On a continental scale, Hacker et al. (1998) found that complementary areas selected on the basis of threatened primate species tended to capture a greater proportion of total primate species richness than when using more indiscriminate methods of selection. They found a similar picture at the local scale where high primate species richness correlated with a high proportion of threatened and high conservation status species. The method was also used to assess the minimum amount of additional protected area required in Newfoundland, Canada to increase the protection of provincially rare plants from 60 to 100 per cent. Out of 78 areas selected using a computer model, only 13 were selected from existing protected areas, suggesting that the existing protected area network is inadequate (Nantel et al., 1998).

Many of the procedures used for identifying areas for protection involve some form of computer modelling. An interesting paper by Freitag \& Van Jaarsveld (1998) looked at the effect on the outcomes from such models of varying different kinds of data input. They used sensitivity analysis to evaluate the impacts of varying degrees of survey intensity (the number of data records for a region), survey extent (the size of the area for which data existed) and taxonomic diversity (the 
number of species for which data existed in a region). Their results suggested that detection of taxonomic diversity was the most important dataset in efficiently selecting areas for protection, with survey extent coming next and finally survey intensity.

Selection of a protected area can be particularly problematic when dealing with species that depend on habitat patches that are both spatially and temporally variable, as in the case of nomadic larks in the semi-arid Nama-Karoo, South Africa. The granivorous adult larks (Alaudidae) can feed anywhere in the Karoo but their insectivorous young depend on the high insect abundance that occurs in areas where grass has grown and set seed as a result of recent rainfall, which is very variable. The grassland areas are attractive to domestic livestock which could prevent successful breeding by the larks. Using a spatio-temporal model Fahse et al. (1998) concluded that neither one large protected area nor numerous small ones would provide the optimal solution but the model could help to define the direction of further field studies.

The general inadequacy of some protected-area networks has been highlighted by the short comings of the African national parks network. According to Siegfried et al. (1998), Africa's national parks were generally small with only two over $50,000 \mathrm{sq} \mathrm{km}$ and there was great variability in the number and size of parks and the proportional area covered by national parks across the continent. Most worryingly the degree of isolation of most parks is likely to prevent the large scale movements that are characteristic of many African savannah species. On a more local scale Namibia's protected-areas network, not set up with biodiversity in mind, covered 13.8 per cent of the country's land area but some important biomes were poorly protected or in the case of Mountain Savannah, a biome unique to Namibia, not protected at all (Barnard et al., 1998).

One example of a biologically based approach to the selection of protected areas is the proposed reserve network in 46 European Union Special Protection Areas for birds in Denmark (Madsen \& Clausen, 1998), intended to protect overwintering and migrating waterfowl from hunting and other leisure activities. Another example is the allocation of conservation units to protect world-wide tiger populations. Using a hierarchical approach, Wikramanayake et al. (1998) divided the tiger range into distinct bioregions, then identified tiger habitat types within each region and delineated conservation units throughout the bioregions, ranked on the basis of habitat integrity, poaching pressure and tiger population trends. On this basis they were able to identify priority areas for research and funding. They discovered that protected areas covered only small areas of tiger conservation units and concluded that protected areas needed to be increased in number, linked and buffered by natural habitat.

Jessamy Battersby

References

Barnard, P., Brown, C.J., Jarvis, A.M., Robertson, A. \& van Rooyen, L. (1998) Extending the Namibian protected area network to safeguard hotspots of endemism and diversity. Biodizersity and Conservation, 7, 531-547.

Fahse, L., Dean, W.R.J. \& Wissel, C. (1998) Modelling the size and distribution of protected areas for nomadic birds: Alaudidae in the Nama-Karoo, South Africa. Biological Conservation, 85, 105-112.

Freitag, S. \& Van Jaarsveld, A.S. (1998) Sensitivity of selection procedures for priority conservation areas to survey extent, survey intensity and taxonomic knowledge. Proceedings Royal Society London B, 265, 1475-1482.

Hacker, J.E., Cowlishaw, G. \& Williams, P.H. (1998) Patterns of African primate diversity and their evaluation for the selection of conservation areas. Biological Conservation, 84(3), 251-262.

Howard, P.C., Viskanic, P., Davenport, T.R.B., Kigenyi, F.W., Baltzer, M., Dickinson, C.J., Lwanga, J.S., Matthews, R.A. \& Balmford, A. 1998. Complementarity and the use of indicator groups for reserve selection in Uganda. Nature, 394, $472-475$.

Masden, J. \& Clausen, S.P.P. (1998) Establishing a reserve network for waterfowl in Denmark: a biological evaluation of needs and consequences. Biological Conservation, 85, 241255.

Nantel, P., Bouchard, A., Brouillet, L. and Hay, S. 1998. Selection of areas for protecting rare plants with integration of land use conflicts: a case study for the west coast of Newfoundland, Canada. Biological Conservation, 84(3), 223234.

Reid, W.V. (1998) Biodiversity hotspots. TREE, 13(7), 275-279.

Siegfried, W.R., Benn, G.A. \& Gelderblom, C.M. (1998) Regional assessment and conservation implications of landscape characteristics of African national parks. Biological Conservation, 84, 131-140.

Van Jaarsveld, A.S., Freitag, S., Chown, S.L., Muller, C., Koch, S., Hull, H., Bellamy, C., Krüger, M., Endrödy-Younga, S., Mansell, M.W. \& Scholtz, C.H. (1998) Biodiversity assessment and conservation strategies. Science, 279, 2106-2108.

Wikramanayake, E.D., Dinerstein, E., Robinson, J.G., Karanth, U., Rabinowitz, A., Olson, D., Mathew, T., Hedao, P., Conner, M., Hemley, G. \& Bolzey, D. (1998) An ecologybased method for defining priorities for large mammal conservation: the tiger as a case study. Conservation Biology, 12(4), 865-878. 